distant from $\eta$ Serpentis, which star is further to the westward.

The Chromospheric Spectrum without an Eclipse. -In the March number of the Proceedings of the U.S. National Academy of Sciences, W. S. Adams and Cora G. Burwell describe briefly the results of an investigation of the flash spectrum without an eclipse in the region $\lambda 4800$ and $\lambda 6600$. The full paper will soon be published as No. 95 of the Contributions from the Mount Wilson Observatory. In the first place, it is interesting to record that the total number of lines measured-upon the negatives taken without an eclipse is greater than that obtained from eclipse negatives. Thus Mitchell's beautiful chromospheric spectrum of I905 showed 901 lines, while those here measured number 1027 lines. It is further pointed out that in the photographs taken without an eclipse the wave-lengths of the bright lines have been determined with reference to the dark lines at the limb. A comparison of 5 I2 lines shows that the difference between the wavelengths of the bright lines and the dark lines at the limb gives a value $-0^{\circ} 002$ Angstrom. The preponderance of the negative sign in the case of the individual elements makes it fairly probable that this quantity may be regarded as real. Reference is made also to the marked gain in accuracy for the Mount Wilson results, attributed notabiy to the greater linear scale of the photographs. Some peculiar characteristics of the dark line spectrum of the sun's limb as seen on the photographs of the flash spectrum are briefly decribed, and the identification of the elements to which these lines belong is suggested as a research of decided interest.

The Rotation of Nebulæ.-Prof. Percival Lowell has forwarded two very interesting photographs of the spectra of nebulæ taiken by Dr. V. M. Slipher, both of which are briefly described by the latter. The first is the spectrum of Virgo nebula, N.G.C. 4594, taken in April, I913, with an exposure of 30 hours, together with comparison spectra of vanadium and iron. It was from this photograph and two others, also taken in the same year, all of which showed the nebula lines inclined, that the first direct evidence that nebulæ rotate was secured. In the photograph sent the slit was placed east and west, and the rotation in the sense that brings the west side of the nebula towards the earth. In addition to their inclination the lines have a large displacement, which makes the solar band $G$ nearly coincident with the iron line $\lambda 4326$, thus indicating a velocity of recession of $\mathrm{I}$ IOo kilometres. Dr. Slipher remarks that this was far the highest velocity then known, but "further observations of nebulæ here have revealed others as high." The second photograph is of the spectrum of the Crab nebula, N.G.C. 1952, taken in February of the present year, with I8 hours' exposure, and similar comparison spectra. This is described as "the most remarkable nebula spectrum known." Upon a rather strong continuous background are found bright lines typical of gaseous nebulæ lines. Thus the lines $\lambda \lambda{ }_{5007}, 4959,486 \mathrm{I}(\mathrm{H} \beta)$, $4686,434 \mathrm{I}(\mathrm{H} \gamma)$, seem to be present. The strange appearance of these bright lines is described as follows :- "They seem to be split into doubles, best seen in $\lambda_{5007}$ and $\lambda_{4} 86 \mathrm{r}$ (the inside components of $\lambda_{4959}$ and $\lambda_{5007}$ would be blended). The distance between the components changes with the position in the nebula. It reminds one of the Zeeman effects in a non-uniform magnetic field and implies the origin to be within the atom. However, the maximum separation is quite enormous-40 tenthmetres. A plausible explanation of the spectrum as velocity effects has not occurred to me as yet."

NO. 2372, VOL. 95]
The "Scientific American" and Astronomy.-The Paris Observatory and its work is the subject of an interesting article to the Scientific American (March 13) by Prof. G. A. Hill, of the United States Naval Observatory. The author accompanies his text with two excellent reproductions showing the large transit circle and the eye end of the equatorial Coudé. The history of this famous institution is briefly sketched, and special reference made to the lunar photographs taken by MM. Loewy and Puiseux. In the issue of the same journal for March 2o, Abbé Th. Moreux describes the planet Saturn, its ring system, and the satellites, and accompanies his remarks with a large number of reproductions from early and late drawings. Such articles popularly written and finely illustrated render a great service in disseminating astronomical knowledge, and we hope to direct attention to similar contributions in future issues.

\section{EXPERIMENTAL STUDY OF THE MECHANISM OF WRITING.}

$\mathrm{O}^{\mathrm{F}}$ recent years considerable advances have been made in the experimental study of the complex processes of reading and writing, mainly in the interests of a new experimental science, which is at present calling itself "experimental pedagogy," and at recent meetings of the British Association the Educational Science Section has devoted a good deal of attention to such work. In the Proceedings of the Royal Society of Edinburgh a further contribution to the experimental analysis of the writing process is made in a paper by Mr. James Drever, on the analytical study of the mechanism of writing.

Looked at from the outside, and regarded purely as a mechanical process, the writing act consists of certain movements and co-ordinations of movement of the fingers, hand, forearm, and shoulder. Of these the hand movements and the work of the fingers are the most important. By employing various pieces of comparatively simple apparatus it is possible to separate hand and finger movements, as well as to isolate for observation and study both the pressure of the fingers in holding the writirg instrument and also the pressure placed upon the writing point.

To Prof. C. H. Judd, of Yale, we owe the original idea of a simple piece of apparatus which enables the experimenter to separate hand and finger movements. This apparatus consists essentially of an attachment for the fifth metacarpal, which carries a pencil or style for recording the movement of the hand. The origiral form of the apparatus was defective in several respects, but a modified form described in the above-mentioned paper seems to eliminate most of these defects. By comparing the record of the hand movement with the actual writing we can determine the part played by finger movement. It should be noted, however, that there is one movement of the hand in writing which cannot be recorded in this way. That is the movement known as pronation - the movement round the axis of the wrist.

Records taken with Judd's apparatus yield several interesting results. Some writers use little, if any, finger movements, and most writers, when writing at maximum speed, and especially with the pencil, approximate to this type. Ordinarily, however, in careful adult writing in this country, all the finer work in the formation of the letters is due to finger movement, and this to a greater extent in pen writing than in pencil writing. As a rule the writers themselves are quite unconscious of such finger movements. In the writing of the child, who 
is merely at the learning stage, there is little finger movement, but finger movements develop as facility is acquired.

The isolation of grip pressure in writing is secured
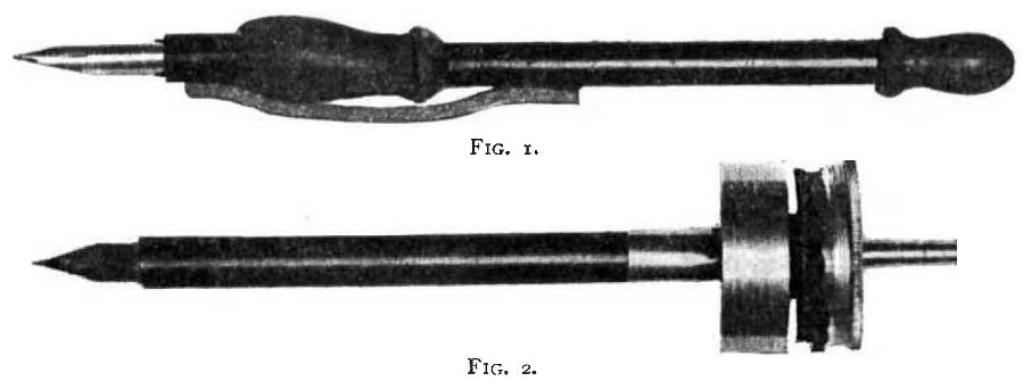

FIf. 2.

by an apparatus consisting essentially of a doublewalled rubber capsule, inserted into the pen or pencil holder to take the grip (Fig. I). The space between the walls, and also the inner space, are filled with mercury. A capillary glass tube passes into the inner space, and its top is connected by means of rubber tubing in the usual way with a recording tambour. Any variations in pressure on the outer wall of the capsule are in this way transmitted to the tambour and graphically recorded by the marking lever on a smoked drum.

Very little work has hitherto been done in the study of grip pressure. The most striking feature in the grip pressure curve obtained is its rhythmical character (Fig. 3, VI ). With the adult this rhythm is extremely regular, but it is absent in the earliest writing of children, first appearing about the age of eleven, and then with marked irregularities (Fig. 3, VII.). In writing with the pencil the grip pressure is considerably greater than in writing with the pen, and the difference between maxima and minima in the rhythm also greater. Finally, there are in adult writing definite indications that a word or even phrase is written with one total impulse.

Severa1 different forms of apparatus have been employed for obtaining a record of point pressure in writing. Continental investigators have employed a writing plate, either connected directly with a lever for marking on a smoked surface, or resting on an air cushion pneumatically connected to a
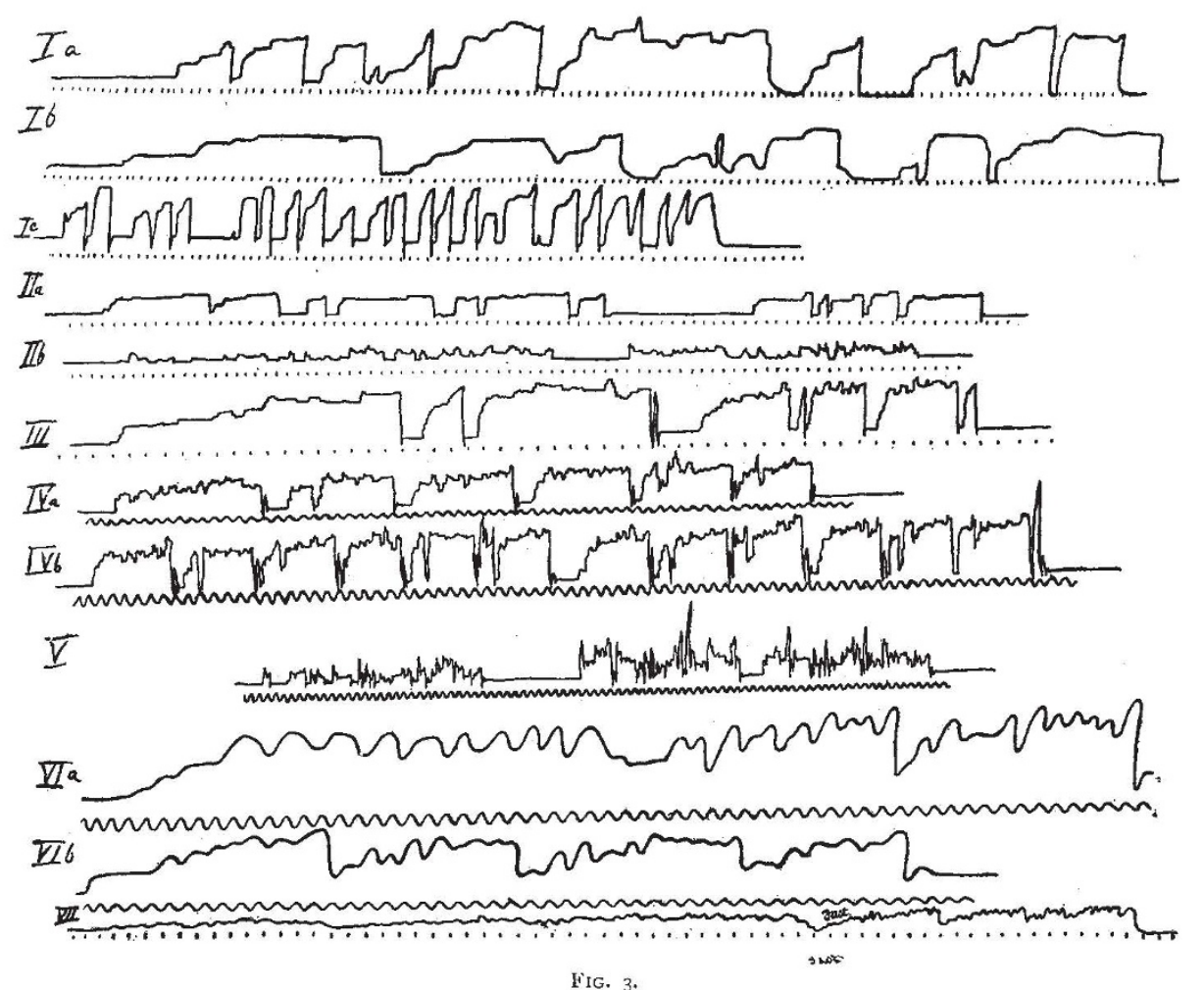

I. to III. Point pressure tracings from children. Time record in seconds by Jacquet Chronograph.

I $a$. Child of six. Words "The cow gives us milk."

16. Child of six (first attempt at script). Words "A "

II a. Pencil writing, and II $b$. Pen writing of child of eight. Words "Moray House School," written twice in each case. III. Child of eleven. Pencil writing. Words "Moray House School," written twice.

IV. and V. Point pressure tracings from adults. 'Time record in secs. by vibrating spring.

IV $a$. Pencil writing, ordinary rate. Words "Moray House School," written twice.

IVb. Pencil writing by same subject, maximum rate. Words "Moray House School," written four times.

V. Pen writing, slow and fast. Words "Moray House School," written once slow and twice fast.

Vi. and VII. Grip pressure tracings from adults and child of eleven. T'ime records for adults in $\frac{1}{3}$ secs. and for child in secs.

VI $a$. Aduit pencil writing. Words "Moray House School."

V1b. Adult pen writing. "Words "Moray House School Moray."

VII. Child's pencil writing. Words "Moray House School" twice, slow and fast.

in each word, and practically no change of pressure with increased speed of writing; further, there is comparatively little increase of speed beyond the ordinary rate, and in some cases the speed actually NO. 2372, VOL. 95] 
diminishes, while the subject thinks he is writing faster.

The pressure curves obtained from children differ from all the adult types. A flat-topped curve had been considered until recently the characteristic child's curve (Fig. 3, II a). This curve does not, however, represent the first stage in the acquiring of writing. The first curves obtained are more or less characteristically drawing curves (Fig. 3, I.). Such curves are best seen where the child begins with printed letters rather than script (Fig. 3, I.c). In this case each stroke requires a definite and separate impulse, and this is well marked in the pressure curve. In the earliest script the curve seems merely irregular, but this is due to variations in the drawing unit with which the child is dealing, which may be a single stroke, a letter, or a group of letters. The second stage in learning to write is marked by what was formerly called the child type of pressure curve, a curve with a strikingly regular, flat top, which is still a drawing curve, though the child is now drawing the whole word. This curve passes gradually into the curve with rippled top of adult writing, the time when the transition can really be said to take place being about the age of ten or eleven (Fig. 3, III.). The transition seems to mean two things. In the first place the necessary co-ordinations are established to such an extent that the mechanism of writing works without attention to the individual strokes and forms which the hand is making. In the second place, and partly because of this, writing has ceased to be drawing and has become language, the rhythmical variations in point pressure corresponding to the rhythmical variations in grip pressure, and being analogous to a certain extent to the rhythm of speech. When this stage is reached the impulse under the direction of which writing takes place is distinctly a word impulse, and sometimes even a phrase or sentence impulse.

It has also been found that the writing of defectives fails to show this characteristic rhythm of adult writing, while drugs like alcohol tend to impair the rhythm and ultimately to break it down altogether, apparently because of their effect on co-ordination. It is also somewhat interesting to find that the pressure curve is almost as characteristic of an individual as his signature, and persists even in left-hand writing without previous practice. There is evidently a wide field for investigation in this direction, and perhaps we may yet see the development of a real science of graphology based upon such investigation.

\section{FLORA OF ADEN.1}

PROF. BLATTER has brought together an interesting account of the vegetation of the Aden peninsula, in which, after summarising the history of botanical exploration of this region from the earliest times, he gives data regarding physiography, climate, soils, tabulated lists of the plants, and brief notes on their distribution, origin, means of dispersal, etc. No references are made to work on plant ecology, but a comparison of the characters of the Aden vegetation with that of other arid regions, as investigated particularly by the Carnegie Institution botanical staff in North American and North African deserts, brings out some points of considerable ecological interest.

The first botanical description of Aden was given by Ibn Batuta in about 1330 , and it consisted of the brief statement that "there are neither seeds nor trees

1 "The Flora of Aden." By Ethelbert Blatter, Professor of Botany at St. Xavier's College, Bombay. Records of the Botanical Survey of India. Vol. vii, No. x. Calcutta, I9 4. Pp. ii 79 ; 5 plates; $x$ map. NO. 2372 , VOL. 95] nor water." Though Aden is not so entirely destitute of vegetation as this famous traveller supposed, the impression it produced upon much more recent botanical visitors was scarcely more favourable. Sir J. D. Hooker, in 1847 , described Aden as being "upon the whole the ugliest, blackest, most desolate, and most dislocated piece of land, of its size, that ever I set eyes upon, and I have seen a good many ugly places"; but he mentioned the comparatively fertile lower valleys, thickly studded with beautiful-flowered shrubs and small trees. Prof. Blatter's compilation is based largely upon the scattered reports and collections made by residents and visitors, and shows that Aden, despite the fact that it consists largely of "bare naked rocks which cannot find their equal in any part of the world as regards dryness, infernal heat, and barrenness,:" possesses an interesting and surprisingly varied vegetation.

The volcanic rocks forming the greater part of the Aden peninsula, which is about fifteen miles in circumference, are practically devoid of plant life; even lichens are scarce on the sun-baked and disintegrating rock-surfaces. These lofty and jagged rocks, rising in places to I $700 \mathrm{ft}$. altitude, are scored by steep gulleys and mostly run straight down to the shore, but here and there the lower slopes are gentle or almost flat, and in such places the clayey soil retains rain-wash, which elsewhere quickly runs off or percolates through the loose soil, and the vegetation in these parts is fairly rich. Apart from such habitats, the rigorous character of the conditions with which the Aden plants have to contend may be realised from the facts that there are no permanent streams or springs or marshes or ponds; the annual rainfall rarely exceeds six or seven inches in the wettest years; no rain may fall for two years at a time, and when it does fall it usually comes down in a torrent lasting for a day or two, changing the dry gulleys into turbulent streams which quickly dry up again.

The Aden flora consists of 2.50 species of flowering plants, including ten trees, fifty-eight shrubs, forty-six undershrubs, and ${ }_{13} 6$ herbs. The work of the Carnegie Institution botanists has shown that in the most arid regions of the earth, where the rainfall is extremely scanty, infrequent and irregular, what were formerly regarded as the typical desert-plants, namely, species with fleshy water-storing leaves and stems (cacti, etc.), are almost or entirely absent, and that the desert type par excellence is not succulent, but sclerophyllous. This term is applied to plants which do not store up water but contend with the extreme aridity of their environment by various adaptations for reducing water-loss to a minimum-reduced leaf surface, dense hair-covering, waxy cuticle, gummy epidermis, development of leaves or branches or both as spines, etc. From Prof. Blatter's iist such plants appear to be dominant in the vegetation of Aden; fleshy species are practically confined to the seacoast. A further point of interest is that about half of the herbaceous plants listed for Aden are shortlived annuals, which grow in the clayey soil of the flats and gentle slopes where water can be retained in the surface layers long enough for these plants to complete their brief life-cycle whenever rain comes. This, again, is a characteristic feature of the typical desert flora with clayey oases.

The records of the Botanical Survey of India contain so much that is, at any rate potentially, of general interest to students of plant ecology, that while the material they contain is welcome and useful, it is much to be hoped that the survey workers will make themselves acquainted with what has been and is being done on modern ecological lines, so that they may 